\title{
An Investigation of Engineers' Use of a Virtual Collaborative Environment for Automated Assembly System Design
}

\section{Dr. Sheng-Jen "Tony" Hsieh, Texas A\&M University}

Dr. Sheng-Jen ("Tony") Hsieh is Professor in the Dwight Look College of Engineering at Texas A\&M University. He holds a joint appointment with the Department of Engineering Technology and the Department of Mechanical Engineering. His research interests include engineering education, cognitive task analysis, automation, robotics and control, intelligent manufacturing system design, and micro/nano manufacturing. He is also the Director of the Rockwell Automation laboratory at Texas A\&M University, a state-of-the-art facility for education and research in the areas of automation, control, and automated system integration. 


\section{An Investigation of Engineers' Use of a Virtual Collaborative Environment for Automated Assembly System Design}

Collaborating over a distance is essential to the business of system integration. Often the key players on system integration projects are in different locations. For example, a system integration firm in the Southeastern U.S. could have a contract with a manufacturer on the West coast to build an assembly line that will ultimately be used in Southeast Asia. In building the system, the system integration firm may need to purchase equipment from multiple suppliers located throughout the U.S. and the world. Currently this occurs primarily via phone, e-mail, and face-to-face meetings, but we expect to see increased use of web conferencing, shared applications and other web-based collaboration tools in the future. Needed are instructional tools that can prepare engineering students to collaborate with other students and/or with industry engineers.

There is an enormous amount of published work in the area of web-based collaborative learning, also known as computer-supported collaborative learning (CSCL) or computer-supported collaborative work (CSCW). ${ }^{1-7}$ Much of this work relates to the use of online classroom tools such as Blackboard Vista ${ }^{4}$ or applications such as chatrooms. ${ }^{5}$ Research in this area has focused not only on instructional effectiveness, but also on personal, social, implementation, and technical issues. However there has been relatively little research on collaborative system design in the area of manufacturing.

To appropriately leverage collaborative technologies for manufacturing system design education, a better understanding of how users work within virtual environments is needed. This paper describes a study to investigate how engineers with varying levels of experience (ranging from experts with 10-15 years of industry experience to upper-level undergraduate engineering technology students) use a virtual collaborative environment for a design task. The goal was to understand how using a virtual collaborative environment impacts engineers' ability to communicate about their design process, with a view toward using collaborative environments to teach students how to design automated manufacturing systems.

\section{Methodology}

A web conferencing tool (Saba Centra) was used to provide a virtual environment for role-play between a design engineer and a customer who needs an automated assembly system. Centra is a market leader in the area of web-conferencing and the investigator was able to leverage his institution's site license to use it. Centra runs on a standard Windows environment and has a web interface, which means users do not have to install special software to use it. It offers a variety of communication tools, including voice over IP (VoIP), internet messaging, a whiteboard, and file sharing. In addition, the presenter can give any other user presenter-level access. Like any other web conferencing tool, Centra works best when higher Internet bandwidth is available.

Five individuals with varying levels of engineering design experience (two senior engineers, one mid-level engineer, and two upper-level undergraduate engineering students) each participated in a one-on-one role-playing exercise with the investigator using Centra. The investigator played 
the role of a customer requesting a design concept for a computer mouse assembly line. The engineers were given a series of mouse part pictures to review (Figure 1) and could ask questions about task requirements (such as the desired cost and timeline and questions about the mouse parts). The Centra web conferencing environment is shown in Figure 2. Data gathered included: length of discussion; types of questions asked; use of affordances in environment such as slides, voice over IP, whiteboard, desktop sharing, document sharing; and quality of design.

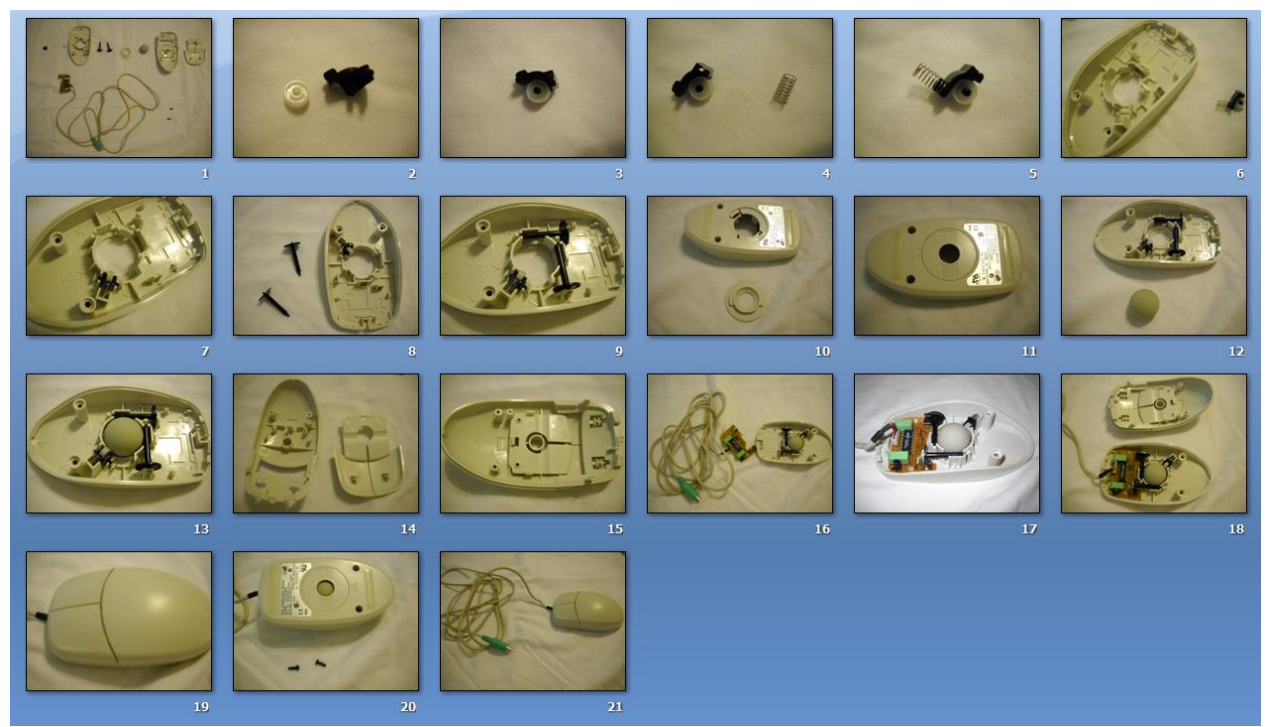

Figure 1. Mouse part assembly pictures.

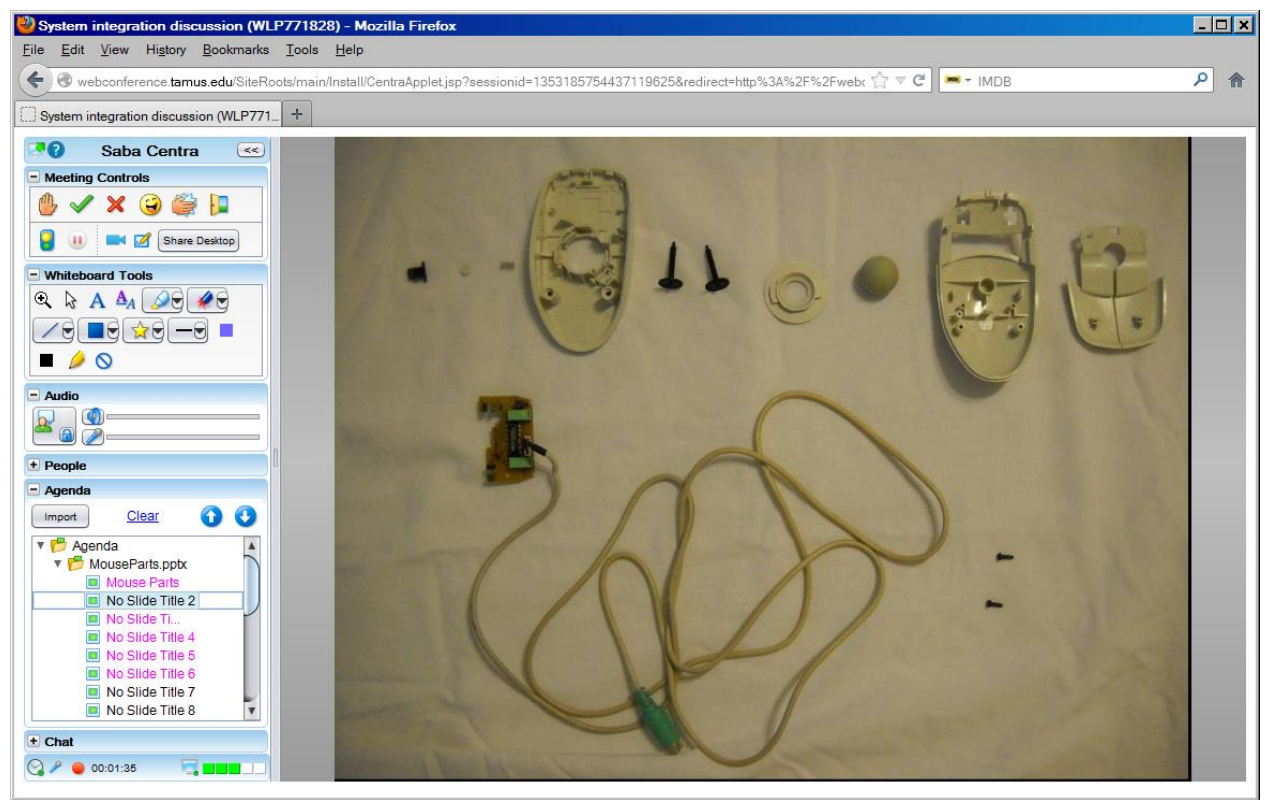

Figure 2. Centra web conferencing environment. 


\section{Findings}

The environment allowed voice over IP (VoIP) communication, a whiteboard, application sharing, and sharing of slides. The clarity of the VoIP was acceptable, but there was a time lag that made normal conversation difficult, especially if the participant did not have a high-speed Internet connection. Often the customer and the engineer communicated by pointing, typing, or drawing on the screen using the whiteboard tools. Some of the engineers were more comfortable using these tools than others.

Below are observations from the experiences of five participants (E1, E2, M1, N1, and N2). E denotes a senior-level engineer, $\mathrm{M}$ mid-level, and $\mathrm{N}$ entry-level.

\section{E1 (Senior-level industry engineer)}

E1 was a senior-level engineer with over 25 years of experience in design and integration of automated systems. He had a slow Internet connection, so there were issues with audio and video lag. He tried to share files on his desktop (a capability allowed by Centra), but it was difficult to see them due to the slow connection. In the end, he and the customer communicated mainly by talking slowly and drawing/typing on the whiteboard.

E1 asked many questions about the design task, such as desired cycle time, budget, current layout, how the parts would be presented for assembly, number of operators (Table 1 lists the questions in more detail). He started to draw after about 28 minutes. Figure 3 shows his drawing. It is intended to be a carousel-type layout, but he had difficulty drawing a circle, so he drew a rectangle instead, with blocks indicating the stations. The design is intended to include nine stations arranged in a circle, with the $1^{\text {st }}$ station adjacent to the $9^{\text {th }}$ station. He used the pink star to point to which part(s) would be assembled at each station as he talked. The design includes five robot stations $(3,4,5,6$, and 9) and four manual stations $(1,2,7,8)$.

Figure 4 shows his typed cost estimates (the text overlap on the first line is due to a video synching issue). He also listed items that would normally be included in a proposal, such as a schedule.

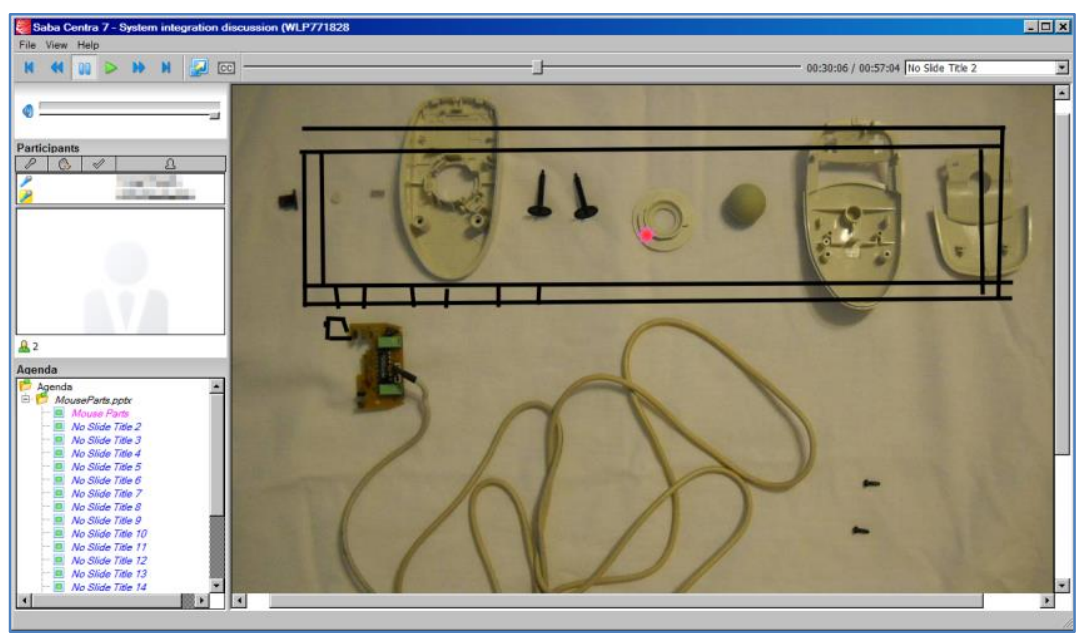

Figure 3. E1 drawing of carousel layout. 


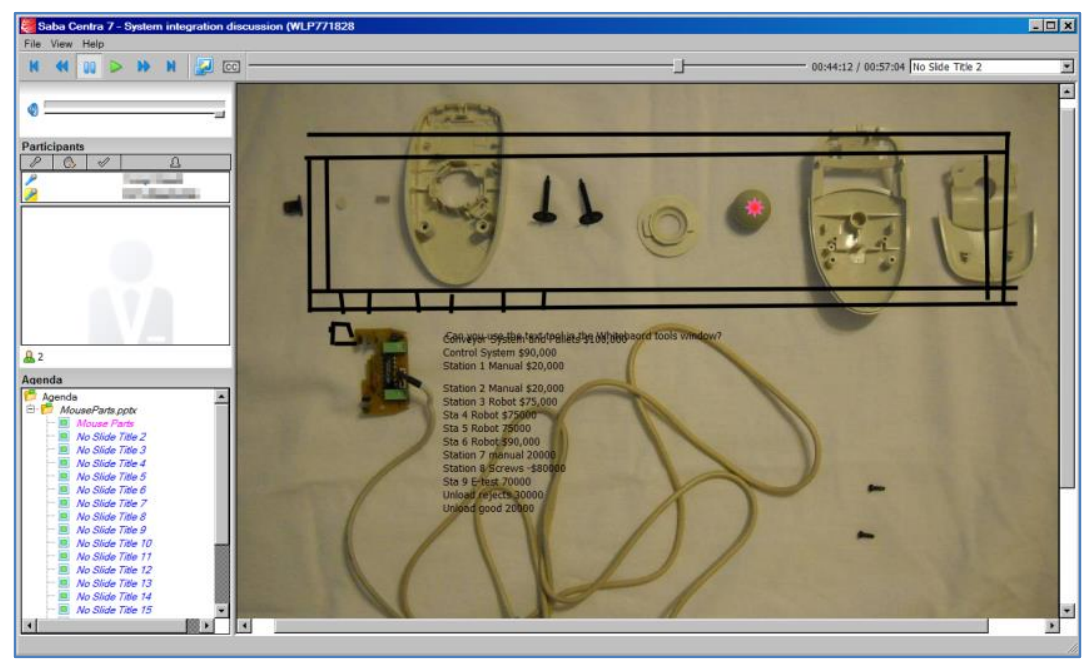

Figure 4. E1 writing in cost information.

In general, E1 seemed to know exactly what to do and what questions to ask, but he had difficulty expressing his ideas in the web conferencing environment, which slowed him down somewhat. Even so, he spent less time on design than any of the other engineer participants (Table 1 shows comparative times). In discussing the environment afterwards, E1 noted that his company does use web conferencing tools, such as WebEx and GoToMeeting, to discuss requirements with customers, but mainly so that customers can show pictures, specifications, and other documents to the engineers. Conversations are handled primarily over the telephone (not VoIP).

E1 commented that his company already uses WebEx (another commercially available web conferencing tool) to interact with clients. He noted that for the initial meeting with a client to discuss a project, face-to-face interaction is preferable, but WebEx is useful for showing details of a design. Their implementation of WebEx does not have as great a variety of tools (such as the whiteboard) as Centra. He noted that if they had more drawing tools available, they could use it to brainstorm about possible designs.

\section{E2 (Senior-level industry engineer)}

E2 was a senior-level engineer with over 15 years of system integration experience. Like E1, E2 asked many questions about the design requirements. He tried to identify the constraints, such as how much automation is desired (how many operators would be used and would the process be fully automatic). He noted that in some countries, using human operators is more cost-effective than automation. He asked how components would be presented to the conveyor line (e.g., would they be on a pallet?). Would the PCB and the cable be presented separately or already connected?

When he started to think about how assembly process will flow, he asked about what fixtures used to pick up or hold parts. He asked how much force would be needed to insert the PCB and cable into the mouse casing. He asked how difficult it would be to hold the spring in place (picture 5 in Figure 1 above) while inserting the spring assembly into the mouse casing. He noted that depending on how tightly attached the spring is to the spring sub-assembly, inserting the spring sub-assembly would probably somewhat easier for a human than for a robot. 
When closing the casing, he asked if the screws would be inserted from the top or from the bottom. He also asked about quality testing. Would the testing occur on one place on the line or multiple places?

He proposed two candidate designs: one with four people and one with three people and a conveyor. He drew his layout and design quickly, but he noted that the whiteboard tools were awkward to use and that being able to draw directly on the whiteboard with a pen device would have been more natural.

Because of issues with the investigator's computer, this session was not recorded, so no time estimates are available. However, E2 was similar to E1 in number and type of questions asked and speed of design.

E2's company is not currently using web conferencing to interact with clients. However, he thought that Centra would be a useful tool. Currently he communicates with customers primarily via phone and e-mail. For large projects, they conduct frequent site visits. A web conferencing tool would offer additional options.

\section{M1 (Mid-level industry engineer)}

M1 was a mid-level engineer with 5 years of experience in industrial automation. Relative to E1 and E2, he asked fewer questions. He did not ask about how parts will be presented. Nor did he not ask for or consider cycle time or talk about line balancing. Figure 5 is a screenshot of M1 brainstorming about sequence of assembly and how to assemble the mouse parts. M1 proposed two different layouts. The first, shown in Figure 6, is a linear assembly line with six stations and six operators. The other layout used an indexing table with six robots.

In general, M1 seemed comfortable with communicating via the web conferencing environment. However, there were technical difficulties: For example, sometimes when M1 would cycle back and forth through the mouse parts presentation, the screen would freeze. Also sometimes the customer was not able to see the cursor when M1 tried to point at an object on the screen.

M1 needed more time to come up with a design than the expert engineers (E1 and E2), and he asked fewer questions, which suggests that he considered fewer possible constraints. However, he asked more questions than the novice engineers (N1 and N2) and was at least twice as fast as either of them in coming up with a design.

Like E2, M1's company is not currently using web conferencing to interact with clients. Also like E2, M1 felt web conferencing would be a useful communication tool. He thought his company probably feels web conferencing is too expensive to use. 


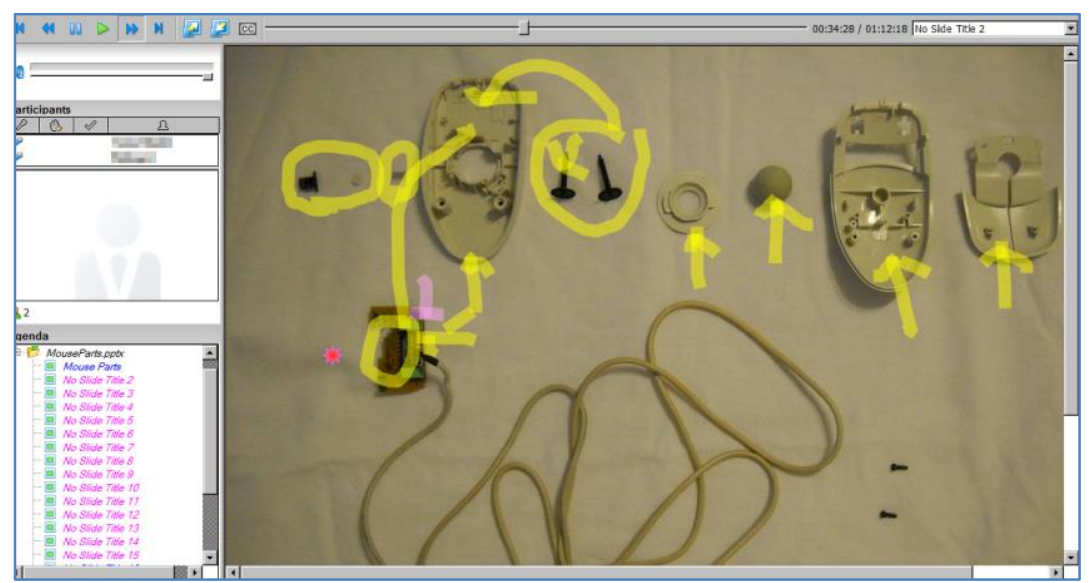

Figure 5. M1 brainstorming about how to assemble the parts.

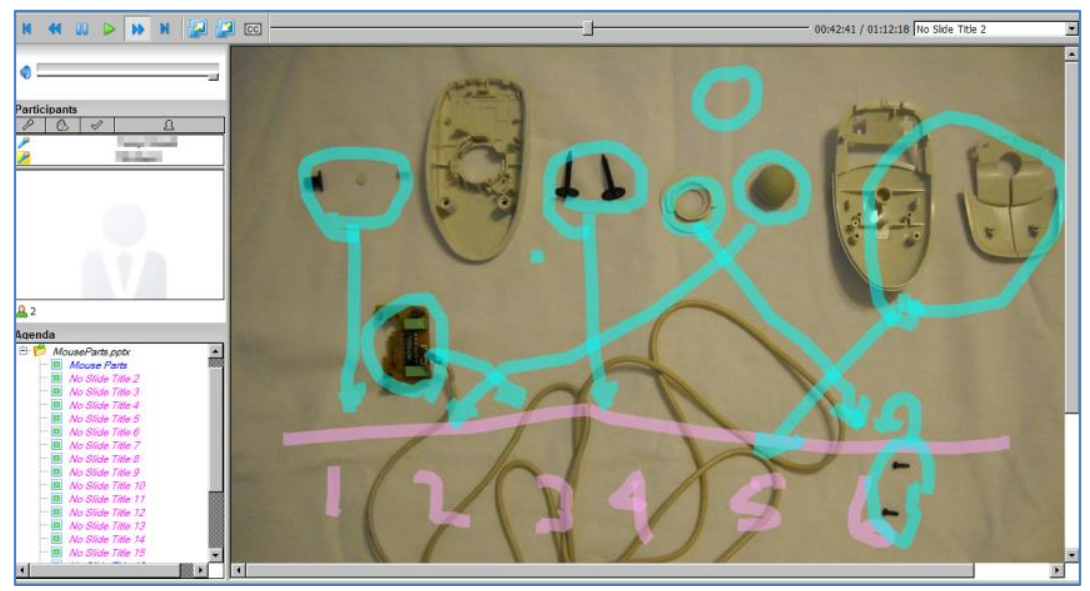

Figure 6. M1 draws linear assembly line.

\section{Engineer: N1 (undergraduate engineering student)}

N1 was an upper-level undergraduate student enrolled in a manufacturing engineering technology B.S. program. He had no industry experience.

N1 assumed that the assembly process would be manual. He did not ask many questions about the assembly constraints before beginning to design.

Figure 7 shows him numbering the mouse parts for later reference. In Figure 8, he begins to sketch the assembly sequence. After he began sketching, he decided to break the assembly process into two separate lines. In Figure 9, he sketches a top-level view showing the main assembly line (line 1) and sub-assembly lines (lines 2 and 3). Later he added station time and cost information. 


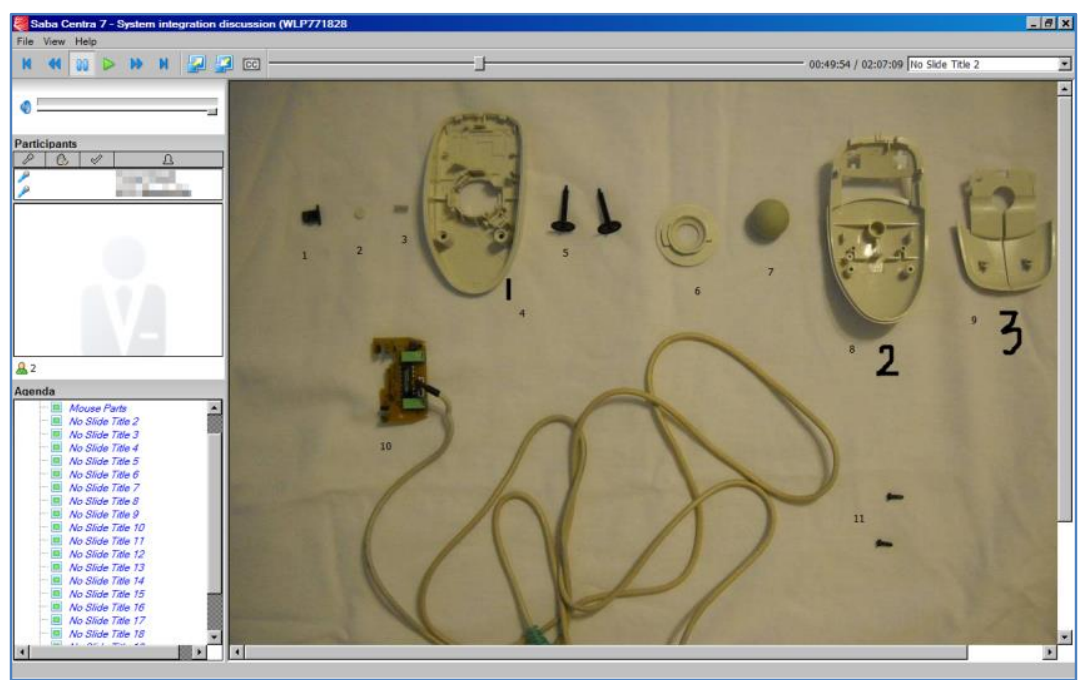

Figure 7. N1 numbers the mouse parts for later reference.

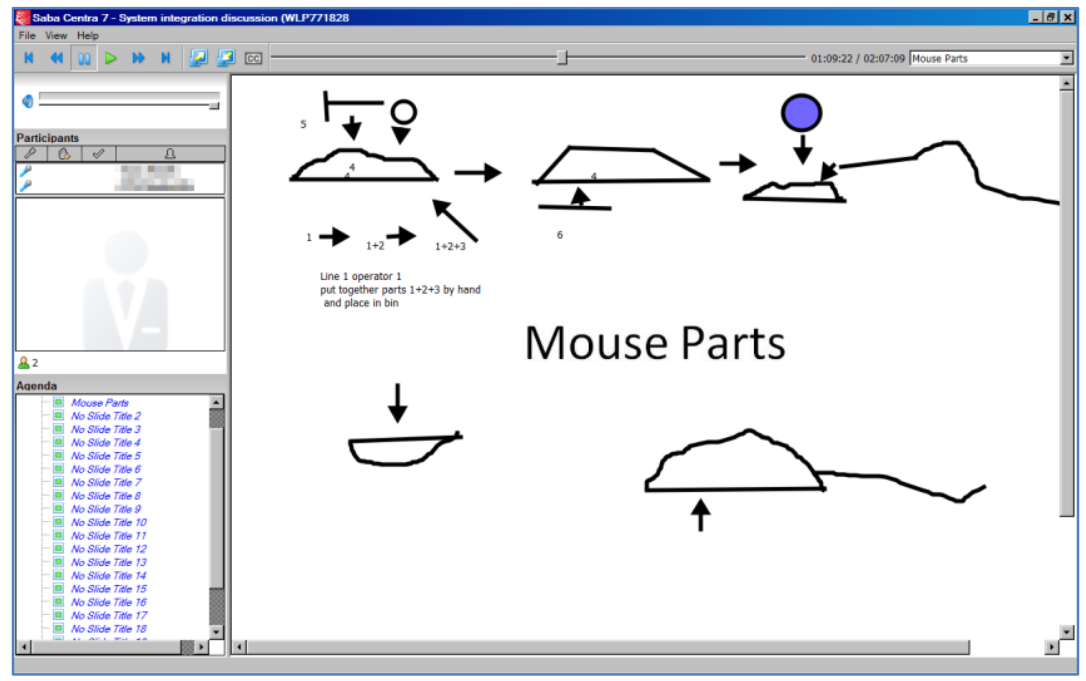

Figure 8. N1 sketches assembly sequence.

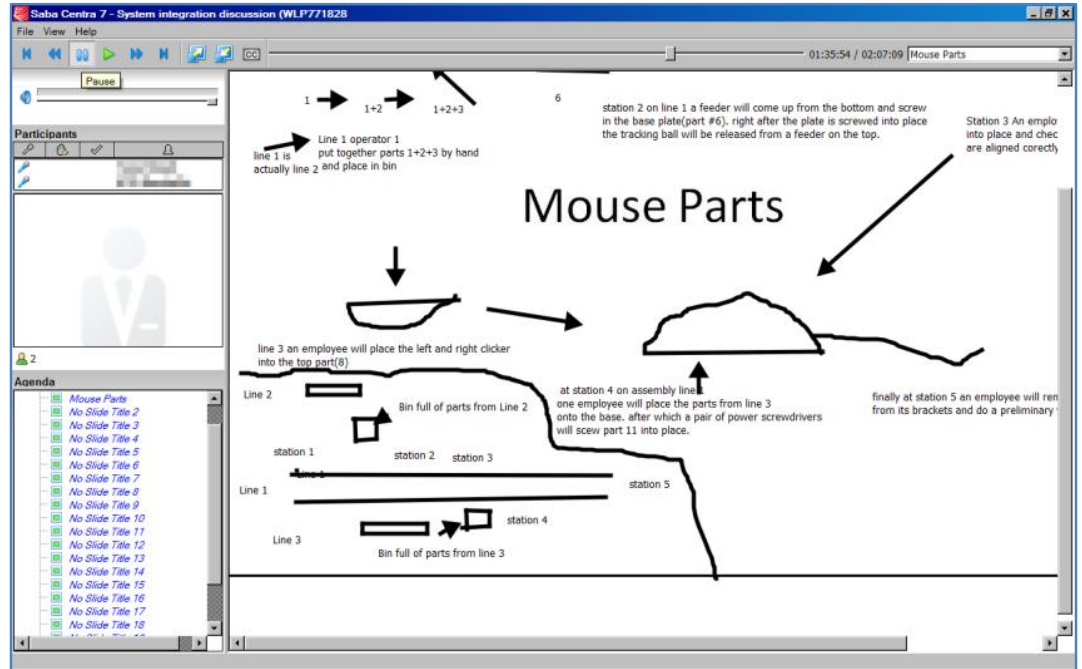

Figure 9. N1 sketches a top-level view showing the main assembly line (line 1) and sub-assembly lines (lines 2 and 3) 
N1 was comfortable expressing himself in the web conferencing environment, but he considered fewer factors than the expert and mid-level engineers did. He asked fewer questions and made more assumptions.

\section{Engineer: N2 (undergraduate engineering student)}

N2 was an upper-level undergraduate student enrolled in a manufacturing engineering technology program. He had no industry experience. Like N1, he did not ask many questions about the assembly constraints; he simply started designing. Figure 10 shows him specifying how the assembly process would work using robots. Figure 11 shows him designing a process using manual operators instead of robots. Figure 12 shows cost and cycle time estimates.

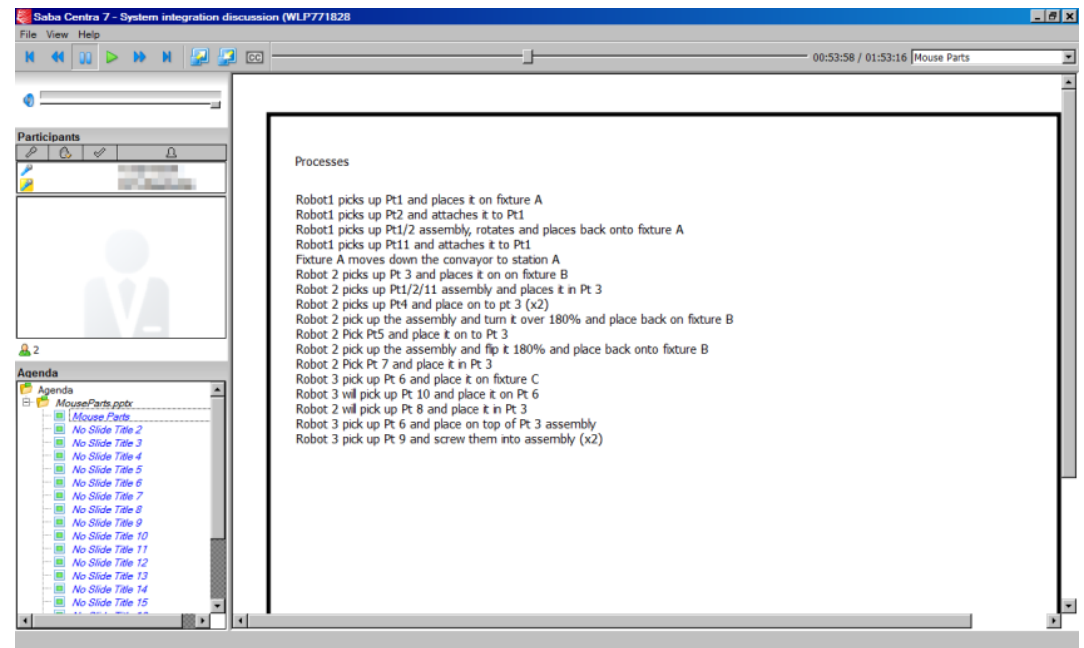

Figure 10. N2 describes assembly process with robots.

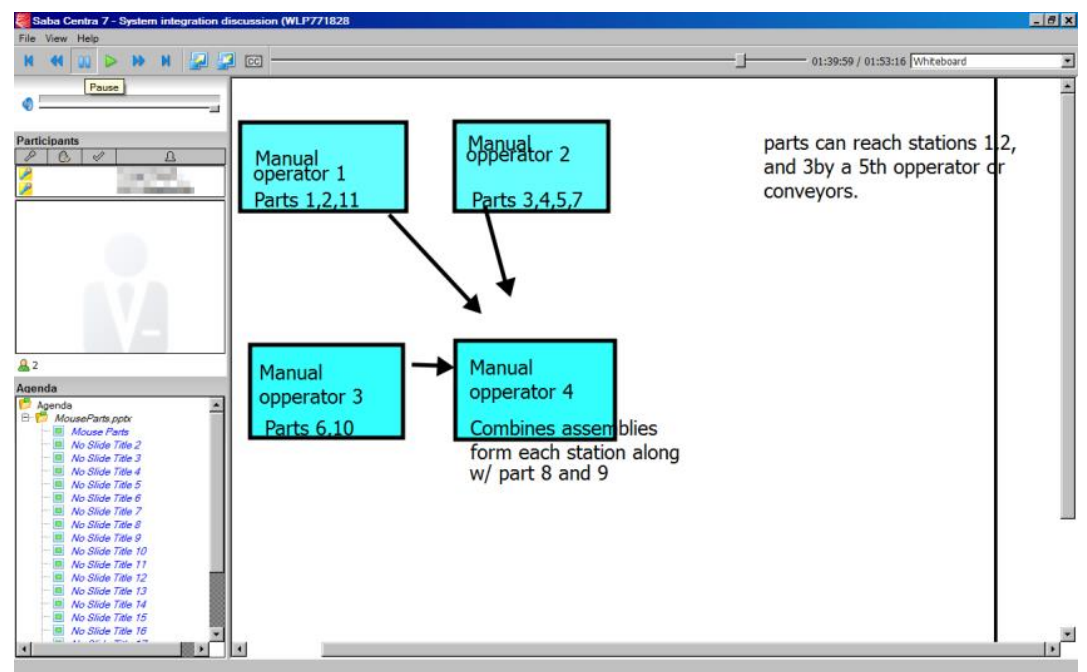

Figure 11. N2 describes assembly functions at each station (assuming manual assembly). 


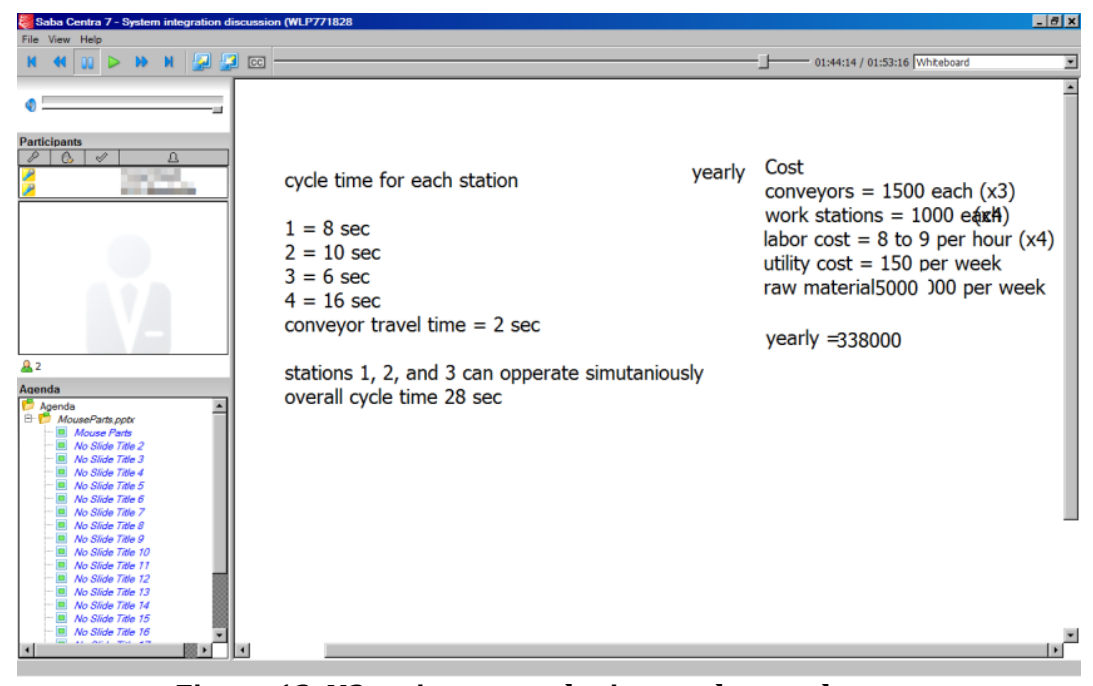

Figure 12. N2 estimates cycle time and annual costs.

Similar to N1, N2 was comfortable expressing himself in the web conferencing environment, but he seemed to consider fewer factors than the expert and mid-level engineers did. He asked fewer questions and made more assumptions. For example, he assumed that the sub-assembly consisting of parts 1,2, and 11 (wheel mount, wheel, and spring) would be able to hold together while being conveyed from Station 1 to Station 4, when in fact some type of fixture would be needed to hold the sub-assembly together for transport and insertion. Also his breakdown of the sub-assemblies was flawed; some sub-assemblies would need to be combined before reaching station 4. Finally, his cost estimates were unrealistically low.

\section{Summary}

We can summarize these results from two perspectives: quality of the engineering design process and usability of the web conferencing environment.

\section{Quality of engineering design process}

Table 1 compares the participants in terms of the types of questions they asked, characteristics of the design process they followed, and time needed to come up with a design. In general, the industry engineers asked far more questions and demonstrated greater awareness of factors that need to be considered and available design options than the students. They also developed their designs more quickly. This is consistent with other studies that have compared expert and novice performance on automated system design tasks. ${ }^{9,10}$ In fact, the experts maintained their edge in design speed and proficiency even though they were handicapped by slower Internet connections than the novices. 
Table 1. Comparison of expert, intermediate, and novice-level performance on design task.

\begin{tabular}{|c|c|c|c|c|c|}
\hline & E1 & E2 & M1 & N1 & $\mathbf{N 2}$ \\
\hline \multicolumn{6}{|l|}{ Types of questions asked } \\
\hline - Cycle time & $\mathrm{X}$ & $\mathrm{X}$ & $\mathrm{X}$ & $\mathrm{X}$ & \\
\hline - Budget/Cost & $\mathrm{X}$ & $\mathrm{X}$ & & & \\
\hline - Current layout & $\mathrm{X}$ & $\mathrm{X}$ & & & \\
\hline - Number of operators desired? & $\mathrm{X}$ & $\mathrm{X}$ & $\mathrm{X}$ & $\mathrm{X}$ & \\
\hline $\begin{array}{l}\text { - Any existing equipment to be } \\
\text { incorporated? }\end{array}$ & & $\mathrm{X}$ & & & \\
\hline - Any physical constraint? & $\mathrm{X}$ & $\mathrm{X}$ & & & \\
\hline - Part presentation & $\mathrm{X}$ & $\mathrm{X}$ & $\mathrm{X}$ & & \\
\hline - What is the orientation of the parts? & $\mathrm{X}$ & $\mathrm{X}$ & $\mathrm{X}$ & & $\mathrm{X}$ \\
\hline $\begin{array}{l}\text { - How will the parts be presented in the } \\
\text { assembly line? }\end{array}$ & $\mathrm{X}$ & $\mathrm{X}$ & & & \\
\hline - How will each part be transferred? & $\mathrm{X}$ & $\mathrm{X}$ & & & \\
\hline - What will each part sit on? & $\mathrm{X}$ & $\mathrm{X}$ & $\mathrm{X}$ & & $\mathrm{X}$ \\
\hline - Are any parts pre-assembled? & & $X$ & & & \\
\hline \multicolumn{6}{|l|}{ Characteristics of design process } \\
\hline - Multiple design options offered & $\mathrm{X}$ & $\mathrm{X}$ & $\mathrm{X}$ & & \\
\hline - Cost estimates realistic and detailed & $\mathrm{X}$ & $\mathrm{X}$ & $\mathrm{X}$ & & \\
\hline $\begin{array}{l}\text { - Design process was fast (seemed } \\
\text { automatic) }\end{array}$ & $\mathrm{X}$ & $\mathrm{X}$ & $\mathrm{X}$ & & \\
\hline \multicolumn{6}{|l|}{ Time needed } \\
\hline $\begin{array}{l}\text { - Duration of web conferencing session } \\
\text { (hr:min:sec) }\end{array}$ & 00:57:04 & N/A & 01:03:18 & 01:56:16 & 01:51:40 \\
\hline $\begin{array}{l}\text { Amount of time spent prior to beginning } \\
\text { design (hr:min:sec) - includes time } \\
\text { spent getting used to the environment } \\
\text { and time spent to understand the design } \\
\text { problem }\end{array}$ & 00:27:31 & N/A & $00: 21: 17$ & 00:36:53 & 00:19:54 \\
\hline $\begin{array}{l}\text { - Amount of time spent on design } \\
\text { (hr:min:sec) - starting from the point } \\
\text { when the engineer begins to draw or } \\
\text { type a design. }\end{array}$ & $00: 29: 33$ & N/A & $00: 42: 01$ & $01: 19: 23$ & 01:31:46 \\
\hline
\end{tabular}

Usability of web conferencing environment

All five participants (industry engineers and engineering students) were able to use the web conferencing environment to gather customer requirements, and to develop and communicate a proposed design. Some participants had slower Internet connections, so voice communication was difficult. Also, some were more adept than others at using the communication tools (such as 
the drawing tools) in the web conferencing environment. However, all were able to get their point across.

Nevertheless, there are some areas that need to be improved to make the Centra web conferencing environment more usable for system design discussions. These include:

- System needs to allow more than one person to use the whiteboard tools at one time.

- When the Internet connection is slow, it is difficult to know who has control of the whiteboard tools at any given time.

- Some participants felt that the online chat was difficult to use.

- Some participants felt that the whiteboard tools were not intuitive. It would be more natural if participants could use a digital pen/stylus to draw on the screen or on a tablet.

- Sometimes the cursor would disappear, making it difficult to know what the other person was pointing toward.

\section{Conclusion and Future Directions}

This study has shown that web conferencing can be a useful tool for assembly line design collaboration, both in industry and educational environments. It can potentially be used for interactions between industry engineers and students and between students and other students. It appears that watching how experienced engineers solve a design problem would likely be beneficial for students. Collaborating or interacting with an industry engineer would be ideal, but even simply observing one would be instructional. Web conferencing affords both.

Directions for future research include involving more than two participants at one time in a design problem-solving activity. Examples of potential collaborative scenarios include:

- All users are learners with similar backgrounds and skill levels.

- One user is an "advisor" (could be instructor or industry engineer); other users are learners. The advisor provides an overview of how to approach the problem and answers questions as needed, but is silent otherwise.

Also in future research, the dialogue between participants in the collaborative problem-solving activity should be recorded to allow qualitative analysis of the audio. In this study, a key reason for using VoIP was to leverage the system's ability to record conversations for data analysis. However, due to issues with the investigator's computer, the conversation audio was not recorded for this study.

\section{References}

1. Hron, A. and Friedrich, H.F. (2003). "A review of web-based collaborative learning: factors beyond technology," Journal of Computer Assisted Learning, 19, 70-79. 
2. Stahl, G., Koschmann, T. and Suthers, D. (2006). "Computer-supported collaborative learning: An historical perspective," in R.K. Sawyer (Ed.), Cambridge Handbook of the Learning Sciences (pp. 409-426). Cambridge, UK: Cambridge University Press.

3. Kreijins, K., Kirschner, P.A. and Jochems, W. (2003). "Identifying the pitfalls for social interaction in computer-supported collaborative learning environments: a review of the research," Computers in Human Behavior, 19, 335-353.

4. Britain, S. and Liber, O. (2004). A framework for the pedagogical evaluation of eLearning Environments. Educational Cybernetics: Reports. Paper 2. Available at: http://digitalcommons.bolton.ac.uk/iec_reports/2

5. Litz, I.R. (2007). Student Adoption of a Computer-Supported Collaborative Learning (CSCL) Mathematical Problem-Solving Environment: The Case of the Math Forum's Virtual Math Teams (VMT) Chat Service. Doctoral dissertation, School of Computer and Information Sciences, Nova Southeastern University.

6. Bystrom, K. and Barfield, W. (1999). "Collaborative task performance for learning using a virtual learning environment." Presence, 8(4), 435-448.

7. Churchill, E.F. and Snowdon, D. (1998). "Collaboratory virtual environments: An introductory review of issues and systems." Virtual Reality, 3, 3-15.

8. Bowman, D.A., Gabbard, J.L. and Hix, D. (2002). "A survey of usability evaluation in virtual environments: Classification and comparison of methods." Presence, 11(4), 404-424.

9. Hsieh, S. "Understanding Automated System Design Problem-Solving: Current Progress and Implications for Instruction," 2009 ASEE Annual Conference, June 14-17, 2009, Austin, TX.

10. Hsieh, S. "Analysis of Verbal Data from Automated System Design Problem-Solving," 2008 ASEE Annual Conference, June 22-25, 2008, Pittsburgh, PA. 